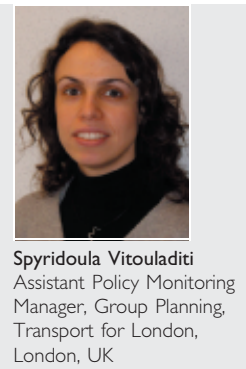

\title{
Central London congestion charging: understanding its impacts
}

\section{Buckingham MSc, A. R. Doherty MSc, CEng, MICE, MILT, D. C. L. Hawkett MSc, CEng, MICE, MIHT} and S. Vitouladiti MEng, MSc, DIC

The origins of a road user charging concept for central London and the development of the central London congestion charging scheme are outlined. The paper then explains the objectives and the main features of Transport for London's programme of impacts monitoring of the scheme. It summarises the main results that were obtained. Drawing on the extensive data from the monitoring programme, the paper then compares the patterns of congestion and traffic flows that were observed in the original scheme and in its western extension. This shows how congestion was initially eased as traffic levels were reduced and how it subsequently increased as the effective capacity of the road network was reduced or reallocated. The paper concludes with some reflections on the achievements of the charging scheme.

\section{INTRODUCTION}

The concept of a congestion charge in central London goes back to the Smeed report (Ministry of Transport, 1964), prepared for the then UK Ministry of Transport. Smeed considered the merits of applying pricing to urban road traffic as a means of dealing with congestion.

The report argued that traffic congestion is the result of road users imposing delays on other road users and that excessive traffic congestion results in an inefficient use of the available road space and a loss to the wider community. This arises because the use of road space is not efficiently priced and so road users are 'immune' to the full cost of the delays they impose on other vehicles. Therefore charging drivers to encourage a more selective and appropriate use of available road space should lead to overall efficiency gains.

Nearly 40 years later, in February 2003, a road user charging scheme was introduced in central London by the mayor, Ken Livingstone, providing the UK's first real demonstration of the approach outlined in the Smeed report.

This paper outlines the scheme's development and introduction and explains the impacts monitoring programme devised by Transport for London as charging authority. It then reviews the overall traffic and congestion impacts of the scheme, which are likely to be of relevance to other central urban schemes. The transport, environmental, social and economic impacts of the scheme are also briefly considered, although the impacts here may be more particular to central London.

More information on the central London congestion charging scheme can be obtained from Transport for London's (TfL's) website. (See www.tfl.gov.uk/roadusers/congestioncharging/ 6722.aspx, in particular the annual Impacts Monitoring Reports that provide more information than can be set out here.) This paper attempts to distil the main implications from all of this background material and from unpublished data and analysis relating to the scheme.

\section{DEVELOPING THE PRICING CONCEPT}

Following Smeed, there were explorations during the late 1960s and 1970s of several potential road user charging schemes in London, mostly in combination with wider traffic, transport or urban planning studies by the Greater London Council. The Greater London Council was abolished in 1986, but in the early 1990s the national government carried out the London Congestion Charging Research Programme (Government Office for London, 1995) which explored several potential charging schemes for central and inner London and looked at aspects of scheme operation using cordon charges. It concluded that congestion charging could be both feasible and worthwhile as a traffic management tool in London, but that there would be substantial technology, public acceptability and political risks surrounding the progression of any actual scheme in the medium term.

In 1998, the government published a white paper (statement of legislative intentions) setting out the proposed powers and responsibilities of a new mayor of London. This included powers to allow the implementation of road user charging schemes in London, and for the revenues to be retained by the charging authority to be expended on transport in London. This 'hypothecation' or retention of the revenues by the charging authority was an innovative aspect of the proposals, intended to make it more acceptable - both politically and publicly.

Meanwhile, the Government Office for London (a regional structure of national government) established a working group of technical experts to explore how a future mayor might use these proposed powers. The group became known as Rocol road charging options for London. In March 2000 the Rocol group published its report (Government Office for London, 
2000), concluding that an area-based charging scheme in central London, with camera-based enforcement, was potentially feasible, effective and likely to be publicly acceptable.

In May 2000, Ken Livingstone was elected mayor of London. His manifesto had included a commitment to consult on a potential road user charging scheme in central London making use of the technical proposals of the Rocol group. Moreover, his advocacy of a road user charging scheme distinguished him from other candidates in the first election for a mayor of London. Following the election and subsequent public consultation the mayor published his transport strategy (Greater London Authority, 2001) in July 2001 with detailed formal proposals for a congestion charging scheme in central London.

As the strategic transport authority created as part of the new governance arrangements for greater London, TfL was then charged with taking forward the development of the scheme. The central London congestion charging scheme was successfully introduced on 17 February 2003, less than 3 years after the mayor's election.

\section{ESSENTIALS OF SCHEME OPERATION}

The original central London congestion charging zone covered $22 \mathrm{~km}^{2}$ in the heart of London, including centres of government, law, business, finance and entertainment. There are relatively few residents in the original zone but it is the employment location for over 1 million people, most of them commuting by public transport. The western extension, introduced in February 2007, is comparable in size to the original zone. The area covered by the extended central London congestion charging zone is shown in Figure 1.

The area covered by the original scheme represents less than $2 \%$ of the total area of greater London and, within the area during charging hours, less than $2 \%$ of vehicle-kilometres driven within greater London. However, congestion in central London was severe during the working day, caused by high intensities of terminating and through traffic. Comparable characteristics also applied to the western extension, although both traffic volumes and congestion were somewhat less intense than in the original central zone before the introduction of charging.

Of particular note from Figure 1 are the various boundary and 'free passage' route arrangements - no charge is made for vehicles using these routes. These are existing high-capacity roads that provide good alternatives for drivers making trips through central London who wish to avoid paying the charge. In particular, a 'free passage route' divides the two halves of the enlarged zone, allowing drivers to avoid paying the charge without diverting too widely around the outside of the enlarged zone.

The basic area charge was initially set at $£ 5$ per day for all chargeable vehicles, applying between 0700 and $1830 \mathrm{~h}$ on

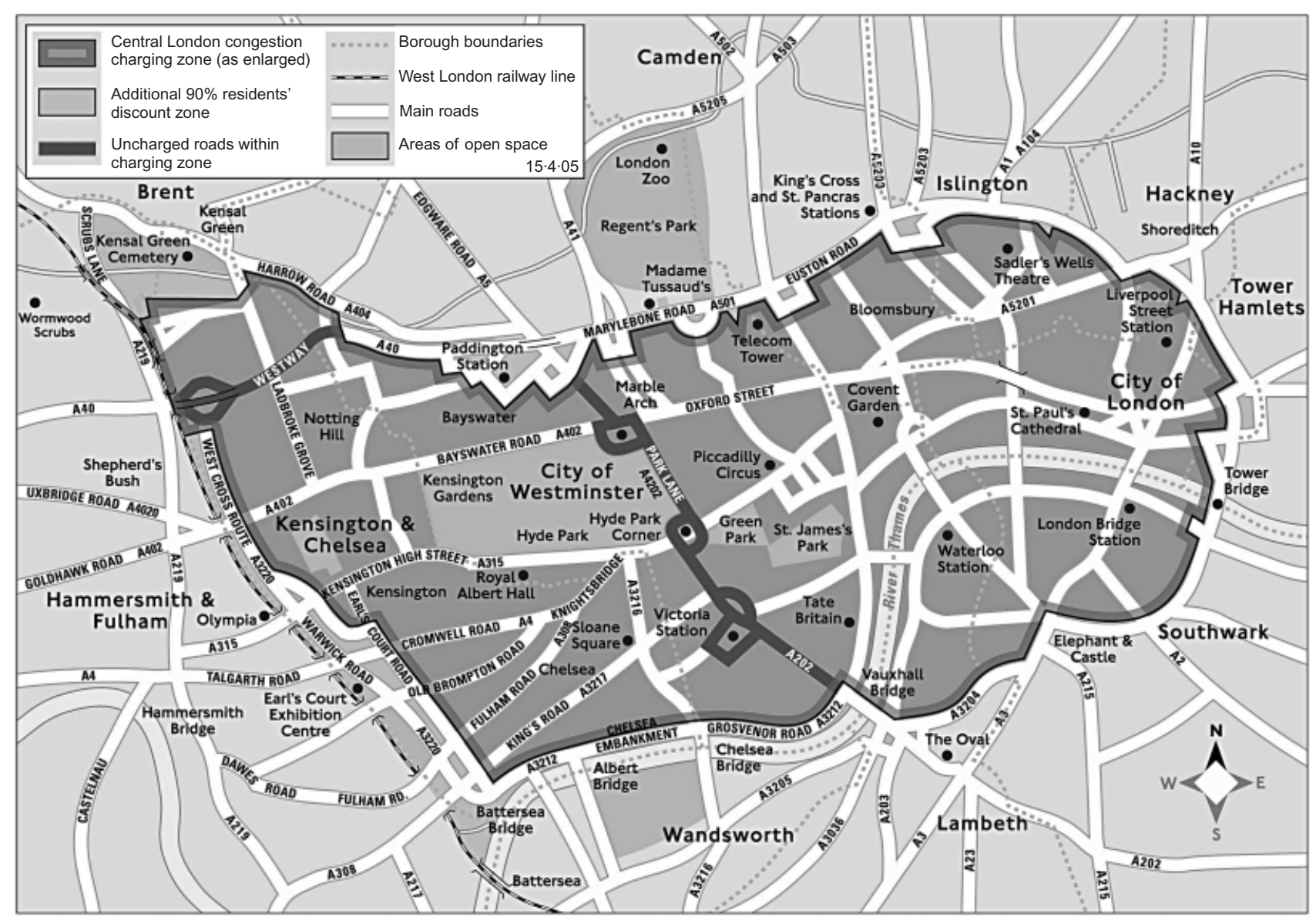

Figure I. Extended central London congestion charging zone (not to scale) 
working weekdays only (revised in 2007 to $1800 \mathrm{~h}$ ). The basic charge does not vary with distance driven, or the time of day at which individual trips are made.

Certain categories of vehicle, notably taxis, London licensed private hire vehicles, motorcycles, pedal cycles and buses, are wholly exempt from the charge. Residents of the zone can register for a 90\% discount from the charge, and disabled persons who are blue badge holders and drivers of certain alternative-fuelled vehicles are eligible for a 100\% discount and pay no charge.

The scheme is kept under continual review by TfL, and various adjustments have been made to the scheme since it was introduced in February 2003. A charge increase from £5 to £8 in July 2005 was intended to maintain the benefits of reduced traffic in central London, although in the event it had relatively little effect on either aggregate traffic volumes or the consequent congestion levels in the original zone.

With the introduction of the western extension in February 2007, the two 'halves' of the enlarged zone function as a single 'extended' scheme, in that one charge payment confers the ability to drive in either of the component zones. Furthermore, residents of each zone benefit from discounted trips in either zone.

More recently, following his election as mayor of London in May 2008, Boris Johnson has proposed removing the western extension, subject to a public consultation and a revision to his transport strategy. The earliest that this could happen is summer 2010.

\section{MONITORING THE IMPACTS OF THE SCHEME}

From the outset the mayor and TfL accorded a high priority to effective monitoring of the impacts of the scheme. In part, this reflected the high profile and controversial nature of the scheme at the time of its introduction. In promoting the scheme the mayor made it clear that, if it did not perform satisfactorily, it would be adjusted. Indeed this flexibility is a strength of any charging scheme: the hours of operation, the level of the charge; the definition of the charging zone; the details of exemptions; and the extent and nature of discounts can all be varied to reflect policy and operational considerations.

TfL's impacts monitoring programme also reflected a wish to capture and understand more fully the responses to - and the implications of - the UK's first major urban road user charging scheme. This meant more than simply recording the effects of the scheme, but seeking to understand how they arose, their implications for London more generally, and what would have happened in the absence of the scheme. Furthermore, although the monitoring work had a strong focus on the more immediate traffic volume and congestion impacts, it also included the important areas such as impacts on business, the economy, the environment, personal (social) circumstances and changed travel behaviour.

The result was a monitoring programme of a scale that had probably never before been attempted in relation to a single traffic management scheme. Findings from the monitoring work are set out in six annual monitoring reports - available from the TfL website. These build into a comprehensive appreciation of the main impacts and achievements of the scheme, the contents of each having a different emphasis, reflecting the evolution of the scheme. Table 1 gives more details.

Five important considerations underpinned the design of the monitoring work; they are listed here.

(a) The need to balance requirements for an early view of impacts with the longer-term imperative to understand the

\begin{tabular}{|c|c|c|}
\hline Report & Publication & Highlights \\
\hline $\begin{array}{l}\text { First Impacts } \\
\text { Monitoring Report }\end{array}$ & June 2003 & $\begin{array}{l}\text { Design of monitoring programme and description of methods } \\
\text { Exposition of baseline (pre-scheme) conditions } \\
\text { Note that a series of 'bulletins' were published during the early months of the scheme - } \\
\text { setting out initial traffic impacts }\end{array}$ \\
\hline $\begin{array}{l}\text { Second Impacts } \\
\text { Monitoring Report }\end{array}$ & April 2004 & $\begin{array}{l}\text { First year summary of traffic and other impacts from introduction of original central London } \\
\text { scheme }\end{array}$ \\
\hline $\begin{array}{l}\text { Third Impacts } \\
\text { Monitoring Report }\end{array}$ & April 2005 & $\begin{array}{l}\text { Consolidated appreciation of traffic impacts of original central London scheme } \\
\text { Findings from social, economic and environmental studies } \\
\text { Summary of scheme operational and enforcement statistics } \\
\text { 'Boundary' case study }\end{array}$ \\
\hline $\begin{array}{l}\text { Fourth Impacts } \\
\text { Monitoring Report }\end{array}$ & June 2006 & $\begin{array}{l}\text { Traffic impacts of original scheme in context } \\
\text { Initial impacts of } £ 8 \text { increased charge from July } 2005 \\
\text { Consolidated view of business and economic impacts of scheme } \\
\text { Initial proposals for monitoring the western extension }\end{array}$ \\
\hline $\begin{array}{l}\text { Fifth Impacts } \\
\text { Monitoring Report }\end{array}$ & July 2007 & $\begin{array}{l}\text { Review of further evolutionary developments with original central London scheme - including } \\
\text { increases to congestion } \\
\text { 'Retrospective' summary of impacts and achievements of original central London scheme - } \\
\text { including ex post economic evaluation } \\
\text { Pre-implementation conditions in the western extension } \\
\text { Initial results following implementation of western extension }\end{array}$ \\
\hline $\begin{array}{l}\text { Sixth Impacts } \\
\text { Monitoring Report }\end{array}$ & July 2008 & $\begin{array}{l}\text { Full treatment of year I impacts of western extension } \\
\text { Analysis of nature and causes of increased congestion in central London }\end{array}$ \\
\hline
\end{tabular}


mechanisms at work. An important - and somewhat surprising - finding was that the main traffic impacts to the scheme occurred and became established almost overnight. There was no prolonged period of 'adjustment', as had been envisaged before implementation.

(b) The need for more than one robust measure of key quantities. Different methods each have particular features and there is rarely 'one simple answer'. In measuring congestion, for example, three different methods gave significantly different estimates of the absolute quantities involved, but very similar estimates of changes and trends.

(c) The need to look outside the charging zone. Much of the benefits from the scheme, such as reduced traffic, road traffic accidents and emissions actually occur outside the charging zone, reflecting the combination of reduced traffic moving to or from the zone with diverted traffic moving around the zone.

(d) Providing for the unexpected. The high media profile of the scheme in its early years meant that TfL had to be in a position to respond at very short notice to specific assertions and claims in the media. This particularly affected the impacts of the scheme on business - where the 'lagged' nature of key business and economy indicators made responding to assertions by those with 'inside information' very difficult.

(e) Finally, a particular difficulty arises with the issue of what would have happened without the scheme. Central London is unique; it cannot be compared directly with anywhere else. Background conditions and influences are difficult to isolate but for many impacts these were ultimately perhaps the major factor in change; some effects are subtle and do not lend themselves to ready observation or measurement; and there was little understanding of the timescales of scheme impacts - how quickly or how slowly would the effects occur.

The results of the monitoring programme have added to knowledge of traffic and transport in London, but perhaps inevitably have also exposed issues that are still being examined and are not yet fully understood. Nevertheless the scheme and its monitoring have contributed significantly to an understanding of the general feasibility, effectiveness and acceptability of urban road user charging schemes.

\section{MEASURMENT OF IMPACTS}

\section{I. Measuring traffic volumes}

Traffic volumes offered the most immediate manifestation of scheme impacts. Although there were several long-established indicators of traffic volumes and trends, traffic monitoring in central London prior to 2002 was surprisingly sparse and not ideal for scheme monitoring purposes. It was therefore necessary to set up an extensive system of new traffic counts, covering the main movements of interest.

The result was an initial system of 20 or so 'key indicators' of traffic volume change, generally organised along strategic counting cordons and screenlines, with some area-based (vehicle-kilometre) counts. Manual classified and permanent automatic counting methods were used in combination, exploiting the relative strengths of both methods. The overall scale of the traffic monitoring effort was unprecedented - involving about 130 permanent automatic sites and in excess of 1000 manual classified counts per year.

\subsection{Measuring congestion}

Measurement of the effect of the scheme on traffic congestion presented greater technical challenges - accentuated by the fact that the anticipated reductions in congestion of between 20 and 30\% was the raison d'être for the scheme - and early feedback on whether this had been achieved was expected.

The first step was to increase substantially the frequency of the established moving car observer surveys in and around central London. Without changing either the established survey method or network coverage, which would ensure historical comparability, the frequency of the survey was increased 18fold. Even this increased scale of coverage fell well short of what would ideally have been required. It meant, for example, that initial indications of scheme congestion impacts would not have been available for 3 months or so after implementation, and even then with unknown seasonal biases and a statistical error that could have been up to one-quarter of the expected scheme-related change.

The automatic number plate reading cameras, being used to enforce the scheme, provided another possible way forward. Cameras record the number plates of passing vehicles, making it possible to calculate average speeds based on successive vehicle transits - where both elapsed time and inter-camera distance are known. A camera-based system was, in the event, successfully developed; its role was primarily to provide very early indications of scheme congestion effects, and to be a longer-term backup indicator for the main (moving car) surveys. More recently, data from global positioning system (GPS) satellites have become available.

\subsection{Secondary transport impacts}

In addition to the traffic volume and congestion impacts, the monitoring work covered a range of 'secondary' traffic and transport impacts. These included understanding the impact of the scheme on public transport in central London - through 'displaced' former car users. In this context the congestion charging scheme needs to be seen alongside other elements of the mayor's transport strategy, which placed great emphasis on the improvement of bus services - both as an essential adjunct to the scheme itself but also reflecting a wider policy priority. Existing TfL data sources provided much of the information required here.

\subsection{Wider social, economic and environmental impacts}

Beyond the immediate impacts of the scheme on traffic, congestion and travel in and around central London there were a variety of wider potential impacts and issues. These ranged across aspects of the impacts of the scheme on individuals and households, on business and economic activity and on aspects of the environment such as air quality. Concerns over many of these had been raised by stakeholders as part of the scheme development process, and TfL needed to be sure that it was in a position both to understand these impacts and to address any issues that arose.

The main elements of the work included large-scale business and social impacts surveys, covering the behavioural, lifestyle, 
cost and adaptation aspects of the impact of the scheme on Londoners, with particular emphasis on 'potentially vulnerable' groups, such as 'key' and shift workers. The work also included assembly and secondary analysis of regional economic indicators, such as business turnover and retail sales trends, and analysis of trends in air quality in and around the charging zone, alongside scheme operational and enforcement details, which primarily arose from TfL's contractors for the scheme.

\section{RESULTS OF MONITORING}

\section{I. Traffic entering and circulating within the zone} In the first year of operation, traffic entering the original charging zone during charging hours was reduced by $18 \%$. Traffic leaving the zone was reduced by $21 \%$. There was a substantial shift in the mix of vehicles circulating inside the zone, with marked reductions of between 30 and 35\% in cars (including minicabs or private hire vehicles); smaller reductions in vans and lorries; and increases in buses, taxis and twowheeled vehicles.

Although remaining impressive figures, it is now clear that since the late 1990s there have been significant 'background' declines to traffic in central London. The introduction of the scheme added, albeit in a very substantial way, to a trend that was already established - and indeed continues.

Figure 2 gives more details of the traffic changes by main vehicle type. Black bars indicate conditions in 2002 before introduction of the original central London scheme; grey bars indicate conditions in 2003 and 2004 following the introduction; white bars indicate conditions following the increase from $£ 5$ to $£ 8$ for the basic daily charge from July 2005. Conditions reflecting the introduction of the western extension are indicated by hatched bars. Note also that historic data have also been normalised to account for the change to the end of charging hours, from 1830 to $1800 \mathrm{~h}$, since February 2007.

\subsection{Boundary traffic}

Traffic on the boundary route for the original scheme has remained broadly stable, with an increase in traffic from vehicles diverting around the outside of the charging zone counter-balanced by fewer trips using the ring road for 'dog leg' movements on radial trips to and from the charging zone. At the junctions around the ring road, which effectively control its performance, local increases in 'orbiting' traffic are generally offset by decreases in radial traffic. The coordination of traffic signal settings around the boundary routes was improved by expanding the use of adaptive traffic control systems.

There was no evidence of significant adverse traffic volume impacts on roads in the 'annulus' outside the charging zone, or outside charging hours. In general, traffic volumes in and around central London have tended to fall year-on-year, reflecting a now well-established trend of background decline.

\subsection{Congestion inside the original zone}

Comparing conditions in 2003 and 2004, immediately after the introduction of the original scheme with 2002 immediately before, as in Figure 3, congestion during charging hours within the charging zone was reduced by an average of about 30\%.

The decongestion impact was broadly similar across the peak

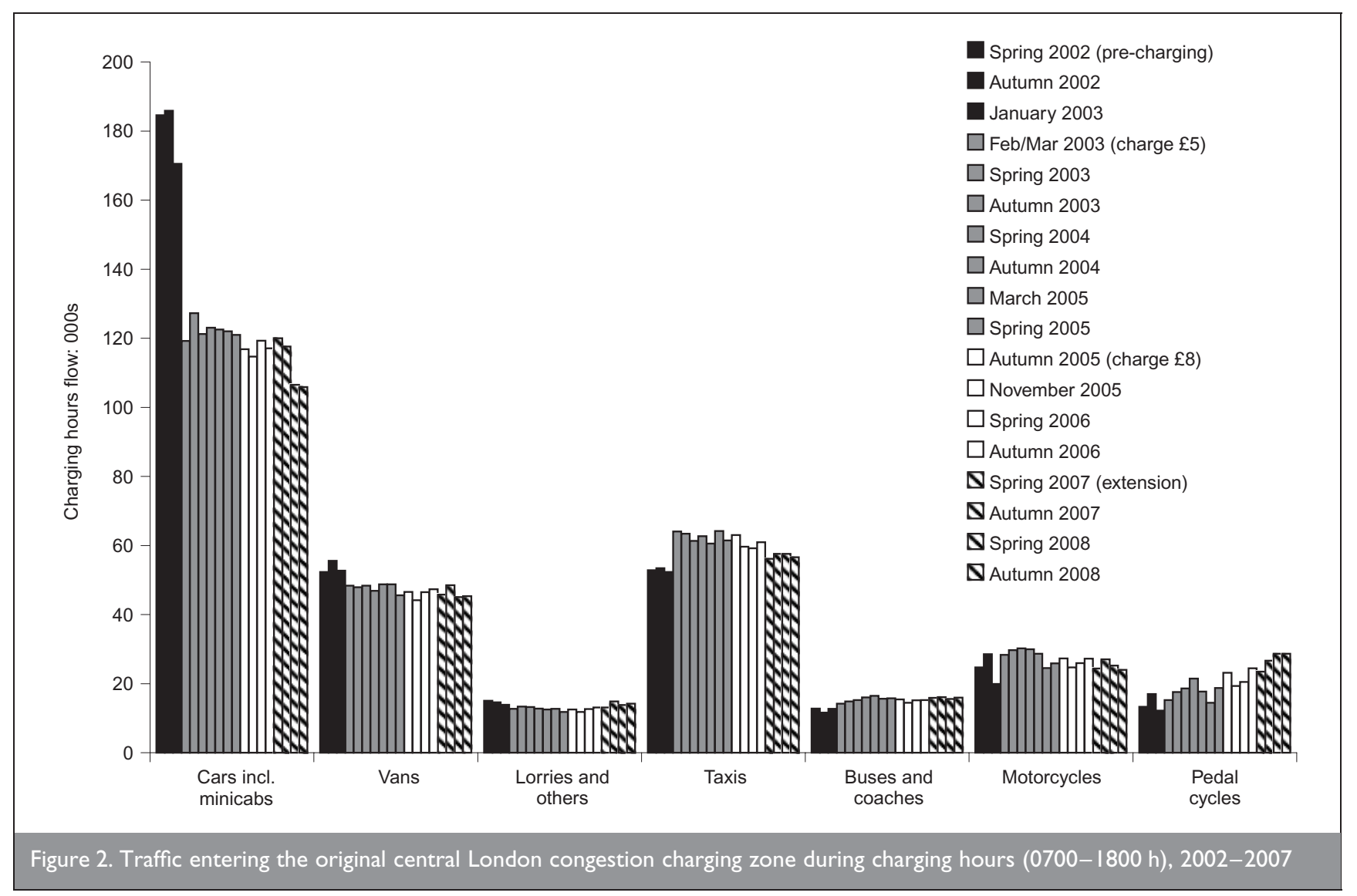




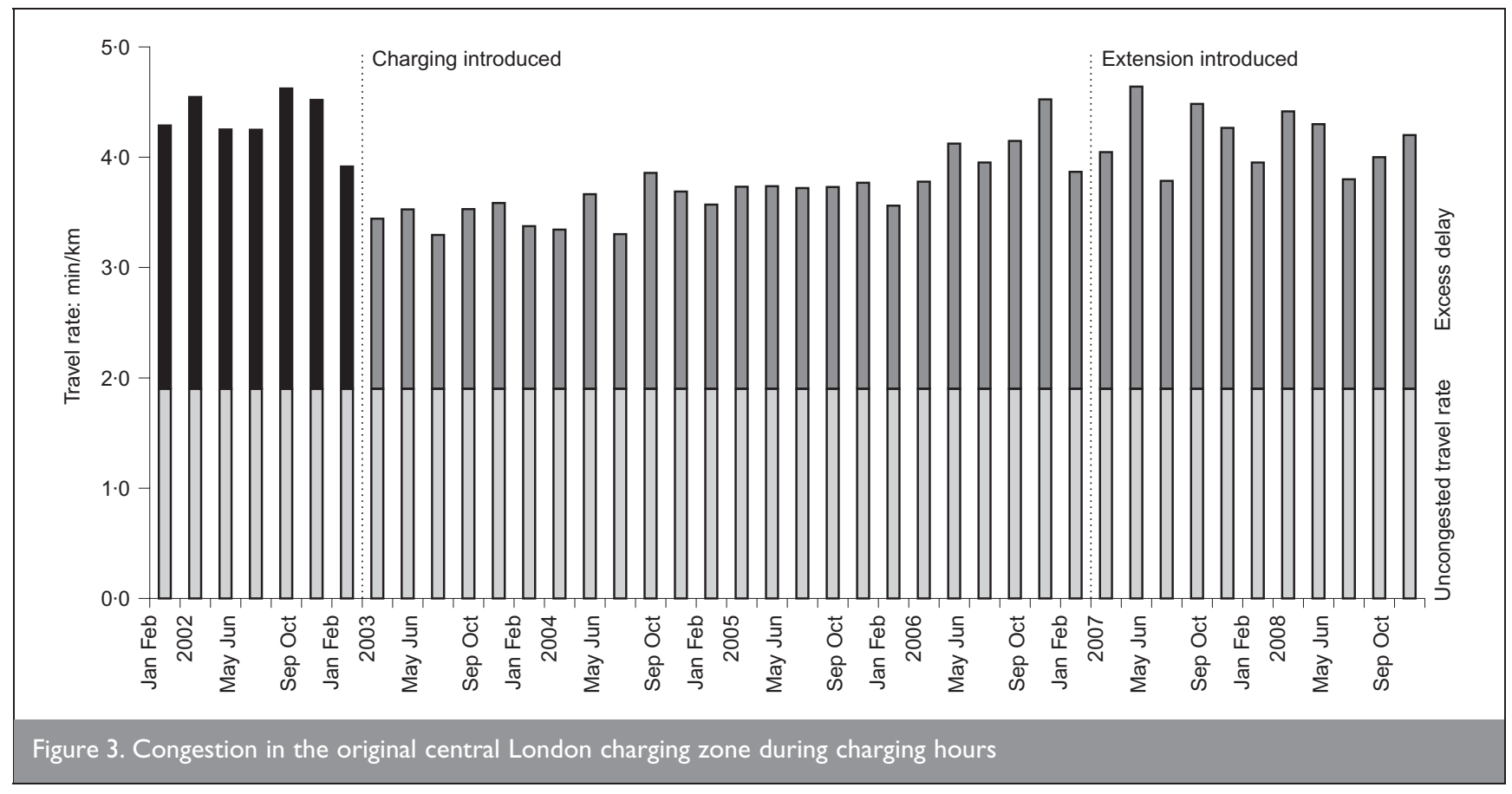

and inter-peak periods, and much of the gains reflected reduced time spent stationary or in queues. This is an important point. Variations in journey times in dense urban road networks are largely determined by the time spent queuing at junctions. The reduced congestion, caused by reduced traffic levels, was mainly reflected in shorter queues at junctions with less time spent by vehicles stationary or in 'stop-start' conditions. Speeds moving between junctions did not materially increase.

Visible from the figure is the trend towards returning congestion in more recent years. This has been a considerable source of concern - as for some time the causes were not immediately obvious. Traffic was not returning to the zone, which would have reflected a diminishing deterrent effect of the charge, but was in fact continuing to decline slowly, reflecting background trends.

Analysis in TfL's sixth annual impacts monitoring report showed that a primary cause of increased daytime congestion was an increase in the number and severity of road and street works, alongside other 'temporary' disruptions. There was also a more pervasive underlying trend towards reduced effective road network capacity - reflecting more 'permanent' interventions. These included changes to the number and timing of traffic signals, 'urban realm' schemes of various kinds, road safety schemes and changes to the mix of traffic and priority accorded to different vehicles. Although many of these interventions had beneficial effects in other respects, such as reduced road traffic casualties, much of the capacity 'freed up' by congestion charging had ultimately been reallocated, at the cost of returning congestion for charge payers.

This 'return of congestion' was seen in a more dramatic fashion following the introduction of the western extension in February 2007. As Figure 4 shows, congestion in the latter part of 2007 was at similar levels to that prevailing before the introduction of the scheme. Here, analysis suggested that onethird of the 'lost' capacity could be traced to the combination

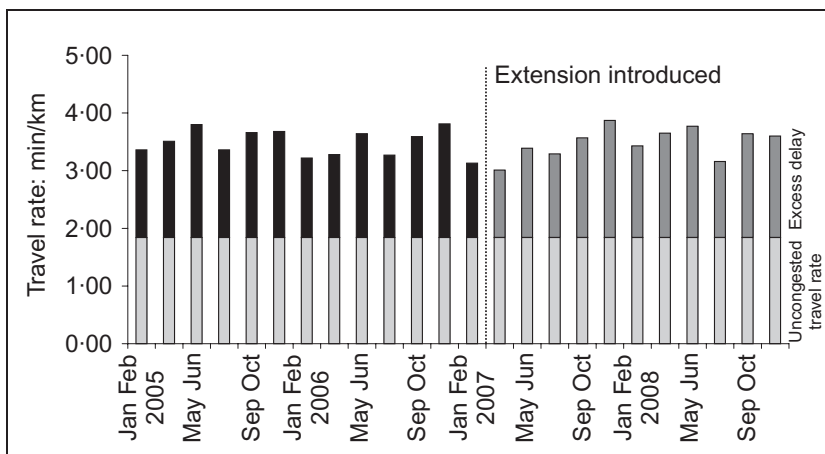

Figure 4. Congestion in the western extension during charging hours, 2003 to 2008

of a major but unfortunately located construction project and changes in the pedestrian facilities at a nearby traffic-signalled junction in Knightsbridge, with another one-third reflecting the replacement of Victorian infrastructure such as water mains an acknowledged priority for London.

The impact of congestion charging therefore needs to be assessed in this context. Sustained reductions to the levels of traffic in the central zone mean that, when compared to conditions that would prevail without the scheme, congestion charging is continuing to deliver congestion relief that is broadly in line with the initial percentage reductions experienced in the early years following the introduction of the scheme.

\subsection{Use of public transport for travel to, from and within central London}

In the first year of the operation of the scheme, passengers entering the original central charging zone by bus increased by around 37\% during charging hours. Up to one-half of that growth was estimated to have reflected displaced car users transferring to the bus network because of the charge. The remainder of the growth reflected wider improvements to bus 
services - a major policy priority of the then Mayor. On the Underground, the economic slowdown of 2002/03 complicated assessments and the aggregate number of passengers at charging zone stations actually fell in the short term.

\subsection{Other key impacts}

The scheme contributed to safer roads. It is estimated that the lower volume of circulating vehicles in the original zone and its boundary route directly leads to between 40 and 70 fewer reported personal injury road traffic collisions per year. This is against a wider backdrop of substantial year-on-year falls in reported road casualties, at least in part due to wider Mayor's Transport Strategy initiatives. It is too early to judge whether a comparable effect has occurred in the western extension.

The central London economy has performed strongly since the introduction of charging. This was an area of particular concern with the original scheme. Contrary to the expectations of some commentators, the growth in the profitability of the retail sector in central London has been comparable to that seen more widely across London, and recent growth has been roughly twice the national rate. With the benefits of hindsight and the data from a wide variety of sources, there is no evidence that the $£ 5$ or $£ 8$ charges have affected the aggregate economy of central London.

Charging has contributed to reduced emissions of pollutants and greenhouse gases. Reduced traffic levels and improved driving conditions led to a relative improvement in ambient air quality against that which would have prevailed in the absence of congestion charging. It was estimated that congestion charging had been directly responsible for reductions of $8 \%$ in oxides of nitrogen $\left(\mathrm{NO}_{\mathrm{x}}\right), 7 \%$ in fine particulate matter $\left(\mathrm{PM}_{10}\right)$ and $16 \%$ for carbon dioxide $\left(\mathrm{CO}_{2}\right)$. These figures related to an annual average $24 \mathrm{~h}$ day for all emissions from road traffic only.

The scheme has produced net revenues to support the mayor's transport strategy. These have been of the order of $£ 100$ million per year and have been reinvested in furthering other elements of the strategy, predominantly on improvements to London's bus network.

\section{DEVELOPMENTS TO THE ORIGINAL SCHEME}

\section{I. Increase to the daily charge from $\notin 5$ to $\notin 8$}

The increase in the daily charge from $£ 5$ to $£ 8$ from July 2005 was intended to maintain the benefits of reduced traffic, although TfL projected that the incremental change to traffic and congestion resulting from this change would be proportionately less than that arising from the imposition of the original $£ 5$ charge in 2003. In the event, the charge increase took place in the same week as the July 2005 bombings in central London, which caused substantial shortterm disruption to the transport networks and created difficulties for the monitoring of the impacts of the change.

Longer-term, however, TfL was able to detect only small aggregate reductions to the amount of traffic in the zone certainly of a smaller magnitude than initially anticipated and proportionately much smaller than the initial adaptation to the $£ 5$ charge. Two factors appear to explain these effects. The increased charge had a smaller effect on the terminating traffic and virtually no further effect on through traffic; and the consequent more limited congestion reduction appears to have been largely subsumed in the wider trend, prevalent throughout 2006, towards increasing congestion in the charging zone.

\subsection{Impacts of the western extension}

The western extension was introduced in February 2007, with no significant operational or traffic problems. Traffic entering the extension zone has consistently been between 10 and 15\% less than previously, with commensurate reductions in circulating traffic and traffic approaching the zone, as illustrated by Figure 5.

Table 2, which is primarily based on a combination of traffic model assessments and observed data, represents TfL's 'best assessment' of the changes resulting from the western extension.

\section{COST OF IMPOSED DELAYS}

In terms of its congestion impacts the scheme has provided a very practical illustration of the economic theory of road user charging. Prior to charging, traffic was moving around the central zone at a typical network speed of about $14 \mathrm{~km} / \mathrm{h}$. This equates to a travel rate of around $4.2 \mathrm{~min} / \mathrm{km}$. Somewhat more than half of this travel rate was caused by 'congestion' - the additional delay experienced by all vehicles because of the presence of other vehicles.

Network speed can generally be assumed to be linearly related to network flow, with average speed, $s$, in $\mathrm{km} / \mathrm{h}$ equal to $s_{0}$ at zero flow. Such a straight-line relationship was used in the calculations in appendix 2 of the Smeed report, citing earlier work by Wardrop (1952). A clear observed example of the relationship was demonstrated in central Glasgow (Owens and Holroyd, 1973). Then it can be shown that the delay in hours imposed by a kilometre of travel by a marginal vehicle on all other vehicles is given by

$$
\text { Imposed delay }=\left(s_{0}-s\right) / s^{2}
$$

From this, the marginal vehicle-kilometre in central London before charging was imposing additional delays shared across all other vehicles of about $5 \mathrm{~min}$.

Typically a vehicle might travel 5-10 km within the original charging zone per day, and an average value across all vehicles for losses or savings in travel time might be around 40 pence/ min. This implies that before charging, each vehicle imposed costs on the other vehicles inside the charging zone of around £10-20 per day.

When charging was introduced the network travel rate reduced to about $3.5 \mathrm{~min} / \mathrm{km}$, so that each vehicle saved around $0 \cdot 7 \mathrm{~min} / \mathrm{km}$ of delay. The imposed travel rate of the marginal vehicle fell to less than $3 \mathrm{~min} / \mathrm{km}$, equivalent to about £6-12 for vehicle travel of 5-10 km inside the zone.

This value broadly represents the value of the delay that each vehicle using the zone is imposing on other users. A driver 


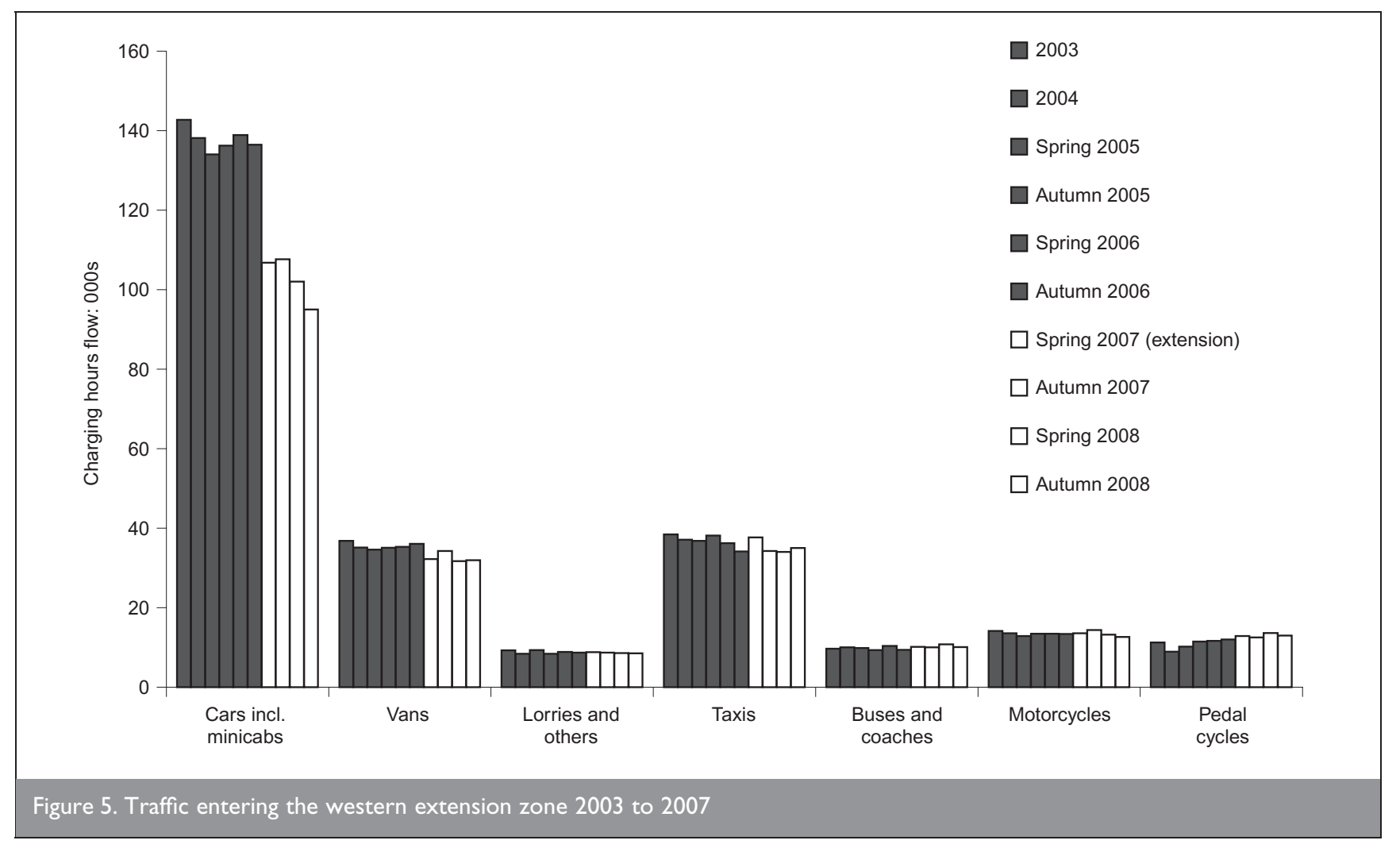

\begin{tabular}{|c|c|c|c|c|c|c|c|}
\hline Trip type & Cars & Vans & Lorries & $\begin{array}{c}\text { Estimated fully } \\
\text { chargeable } \\
\text { vehicles }\end{array}$ & Taxis & $\begin{array}{l}\text { Buses and } \\
\text { coaches }\end{array}$ & $\begin{array}{c}\text { Total } 4(+) \\
\text { wheeled } \\
\text { vehicles }\end{array}$ \\
\hline Before western extension & & & & & & & \\
\hline $\begin{array}{l}\text { Central zone users } \\
\text { Non-central zone users }\end{array}$ & 47000 & 17000 & 5000 & & & & \\
\hline Exempt, discounted & 31000 & 2000 & & & & & \\
\hline Terminating & 47000 & 13000 & 3000 & 64000 & & & \\
\hline Through & 13000 & 3000 & 1000 & 17000 & & & \\
\hline $\begin{array}{l}\text { Observed total } \\
\text { After western extension }\end{array}$ & 138000 & 36000 & 9000 & 81000 & 35000 & 10000 & 227000 \\
\hline $\begin{array}{l}\text { Central zone users } \\
\text { Non-central zone users }\end{array}$ & 50000 & 17000 & 5000 & & & & \\
\hline Exempt, discounted & 31000 & 2000 & & & & & \\
\hline Terminating & 21000 & 11000 & 3000 & 36000 & & & \\
\hline Through & 4000 & 3000 & 1000 & 8000 & & & \\
\hline Observed total & 107000 & 33000 & 9000 & 44,000 & 35000 & 10000 & 195000 \\
\hline Percentage change & $-22 \%$ & $-7 \%$ & $0 \%$ & $-45 \%$ & $0 \%$ & $2 \%$ & $-14 \%$ \\
\hline
\end{tabular}

unwilling to pay this level of charge would have gained less from using the zone than the delay costs that they would have imposed on others.

\section{EFFECTS ON CONGESTION}

Paradoxically perhaps, the more recent trend towards increasing congestion has helpfully demonstrated some underlying characteristics of how the network operates.

Figure 6 shows - to the same scale - the average network speeds in the central zone and the total traffic entering and leaving each zone. This is in effect a combined presentation of the data that inform Figures 2 and 3 for the original central zone, together with the comparable data for the western extension.
Speeds inside each zone have been averaged from the surveys carried out every 2 months to give a total of 12 observations per direction on each surveyed link in each 6 -month period. The traffic flow data are derived from the manual classified counts undertaken in the spring and autumn of each year at all entry and exit points to the charging zones over a 6-week period, approximately in the middle of each 6-month round of speed surveys, recording all vehicle movements into and out of the zones. Observations of vehicles have been converted to passenger car units (pcus).

Ideally, the flow inside each zone, measured as vehiclekilometres, would be used in this analysis. However, this is difficult to measure accurately given the size of the zones. As only a relatively small proportion of traffic is generated within 


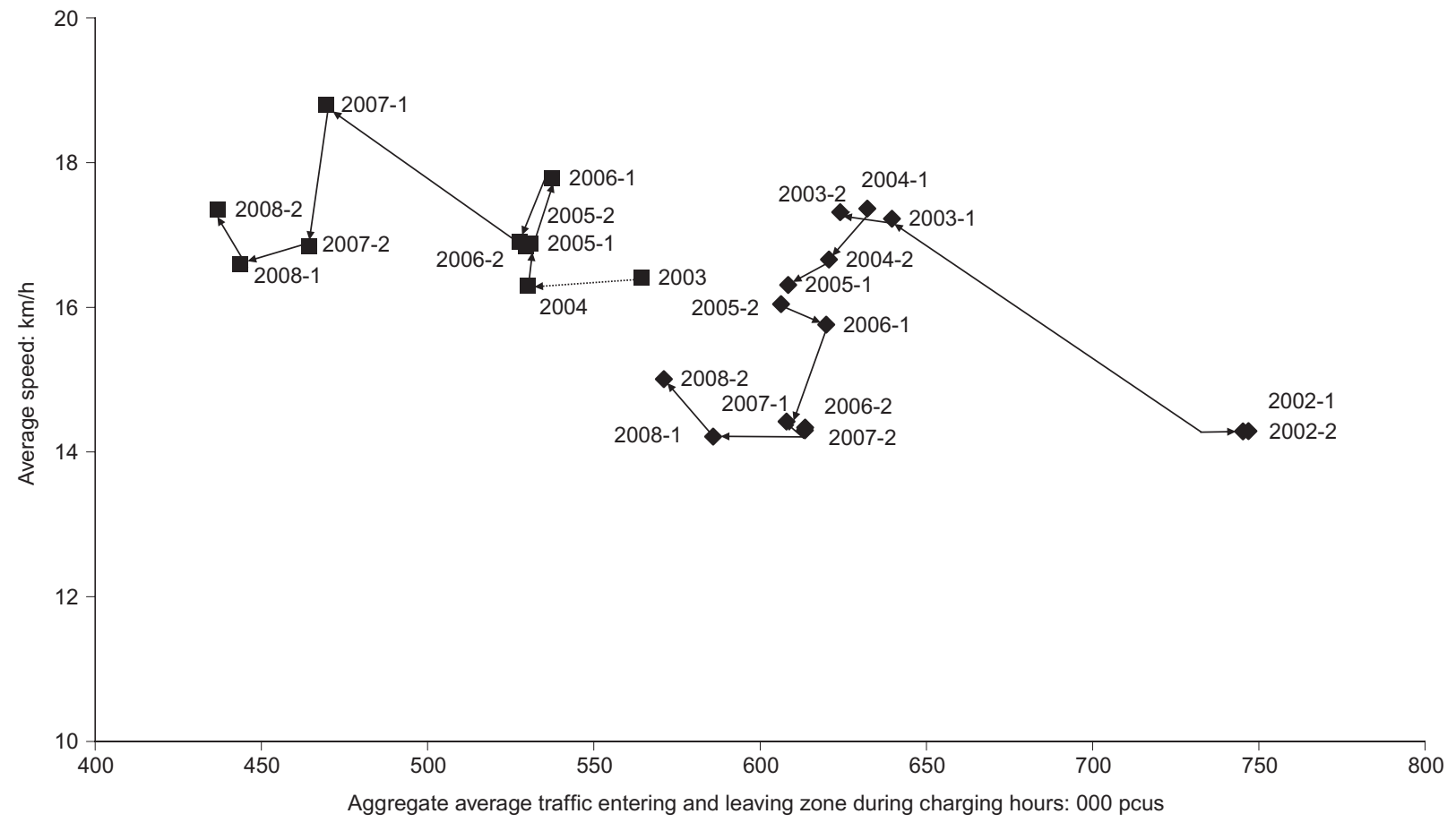

Figure 6. Evolution of average traffic speeds inside the congestion charge zones and traffic crossing the zone boundaries

each zone, the boundary crossing traffic is used as a measure of traffic activity.

The annotation 2002-1 refers to the conditions observed in the first six months of 2002 (January-June); 2002-2 means the conditions observed in the second half of 2002 (JulyDecember). The original charge, introduced in the central zone in February 2003, resulted in boundary crossing traffic reducing from around 745000 pcus in 2002 to 640000 pcus in the first half of 2003, and traffic in the zone travelling about 20\% faster. (January 2003 and early February 2003 data, immediately pre-scheme, have been ignored in assembling data point 2003-1.)

However, between 2004-1 and 2006-2, while boundary flows remained in the region of 620000 to 650000 pcus, average speeds declined from over $17 \mathrm{~km} / \mathrm{h}$ to almost $14 \mathrm{~km} / \mathrm{h}$, with deteriorating conditions particularly evident during 2006-2. From 2006-2 to 2007-2, average conditions were apparently steady, albeit with speeds having returned to pre-charging levels. Between 2007-2 and 2008-2, average boundary flows declined by around 10\% with an indication of significantly improved speeds in 2008-2.

The congestion charging scheme was extended westwards in February 2007. Figure 6 again shows the evolution of average speeds inside the zone and boundary crossing flows for the western extension, starting from observations in the years prior to the extension scheme - although not to the same level of precision for 2003 and 2004. The figure then suggests an apparent reduction in effective capacity between 2006-1 and 2006-2, prior to the introduction of charging in the future extension zone, matching a corresponding reduction in the original zone during the same period.

The effect of charging in the western zone is evident from the decline in traffic levels from 2006-2 to 2007-1, the corresponding increase in traffic speeds from around $17 \mathrm{~km} / \mathrm{h}$ to around $19 \mathrm{~km} / \mathrm{h}$. In the second half of 2007 , however, most of the benefits gained from charging were effectively lost with speeds returning to pre-charging levels even with the reduced level of traffic entering and leaving the zone having been maintained. In 2008-1 and 2008-2 comparable effects to those observed in the central zone are evident from the observations in the western extension. A further decline in the volume of traffic entering and leaving the zone was followed by a small increase in speeds.

The striking similarity in the patterns suggests that the underlying trends are being reliably demonstrated: that the initial reduction in traffic flow inside each zone brings about an improvement in speeds; that this improvement gradually deteriorates; and that a period of broad stability was reached around 2007-2, with average speeds back to pre-charging levels, followed by something of an upturn in speeds with flows declining from 2007-2 to 2008-2.

\section{I. Interpretation}

Figure 6 illustrates the interaction between 'supply' effects (the speed of traffic, as a function of the demand) and 'demand' effects (the change in demand, as a function of the speed of traffic).

(a) Supply effects depend on the network. If the network capacity stays constant, then as demand reduces due to charging then speeds increase.

(b) Demand effects depend on the underlying demand to drive. It is affected by congestion charging.

If the underlying demand to travel stays constant, then as the network gets slower, fewer people will want to drive on it. 
In Figure 6, the initial effect of charging is to reduce demand. Road supply is unchanged. So the jump between 2002-2 and 2003-1 for the central zone demonstrates the supply elasticity: the change in speed of traffic with respect to the flow. The arc elasticity of speed with respect to flow is $-1 \cdot 2$. The corresponding value for the western extension, from 2006-2 to $2007-1$, is $-0 \cdot 9$. These values are close to the value of about $-1 \cdot 0$ that other studies of traffic in central London have indicated.

Once charging has been introduced, the fall in speed and flow for both areas indicates a fall in the network capacity. If the underlying demand is assumed to be constant, the fall in speed indicates a change in the supply. This indicates an arc elasticity of demand with respect to speed of 0.8 in the central zone and of 0.9 in the western extension. Again, these values agree with a value of about $0 \cdot 8$ indicated in other studies in London. The agreement supports the assumption that the change in conditions since the introduction of charging is due to a change in supply - that is, a fall in network capacity.

The fall in both speed and flow since the start of charging has, as Figure 6 shows, shown a tendency for speed to fall more than flow in the first year or two, and for the fall in flow to occur later. This may be at least partly because supply effects are instant, but demand effects take time as drivers gradually change travel behaviour in the light of the slower speeds.

The fall in network capacity since the introduction of charging can be expressed as the change in flow that can be carried by the network for a given speed. In the central zone, the line joining the point at 2002-2 (prior to charging) to the point at 2003-1 (after charging was introduced) enables an estimate to be made of the flow that could have been carried prior to charging at, for example, the $2008-2$ speed of $15 \mathrm{~km} / \mathrm{h}$. This would be in the region of 720000 pcus/day. The actual flow at 2008-2 was 570000 pcus/day: 20\% lower. So there has been a net loss of about $20 \%$ in effective network capacity for road vehicles in the period between 2004 and 2008. Similarly the western extension saw a loss of 15\% of effective network capacity in the 18 months after charging started.

The potential causes of additional delay on the two networks have been considered in the Congestion Charging Annual Monitoring Reports, and mentioned in Section 6 above.

\section{REFLECTIONS ON THE ORIGINAL SCHEME}

More recent TfL monitoring reports have been able to give a longer-term evaluative perspective on the experience with charging in central London, such that it is possible to offer several reflections that will be of wider relevance.

First, the London scheme, with its various developments, has confirmed that charging is practically feasible. It has also generally confirmed the methodologies and theoretical basis behind the concept of road user charging. Initial fears of gridlock outside the zone, mass public confusion and economic desolation have been proven to be unfounded. Taking a longerterm perspective, the advent of charging can be seen as simply another evolutionary step in urban transport planning.

Second in terms of the potential wider applicability of charging, central London was in some respects a particularly suitable candidate. Congestion levels were very high. It is very well served by public transport, and travellers displaced from car to public transport would not overwhelm the capacity of the public transport system. It had a manageable proportion of through traffic. The political decision process, under an elected mayor, was straightforward. Other cities will have different characteristics, notably in terms of public transport provision and political structures, and these will be critical in determining the application and the more detailed nature of any future local schemes.

Third, while the charging arrangements in central London may have been a significant development for transport planners, and for certain individuals who may be directly or disproportionately affected, ultimately it operates in a wider backdrop of potentially more pervasive trends and influences. Most Londoners are not significantly affected by the scheme, and the economic prosperity of central London clearly owes much more to global events and the vagaries of the wider economy than to an incremental change to the relative costs of private vehicle travel which is used by less than 10\% of visitors.

In retrospect the impacts attributable to congestion charging have tended to accentuate positive trends, such as reduced emissions or fewer accidents; or to reverse a negative trend, congestion; or, arguably, to have had a neutral impact on a cyclical trend, economic activity. Meanwhile, the experience with returning congestion in both the original central London charging zone and the western extension shows that scheme benefits need to be closely managed - and that the priorities for the allocation of scarce road space need to be both thought through and clearly articulated.

Fourth, Mayor Livingstone recognised the importance of monitoring - and the transport planning community is now much better off for it. TfL's published information,

comprehensive as it is, is nevertheless merely a summary of a much wider body of knowledge and experience, which will be of long-term value. Charging in central London not only represents one of the biggest and most ambitious transport monitoring programmes but also one that has been actively used to refine and develop policy - and one that has been seen through to a logical conclusion, and its results published.

Finally, the technology for operating the scheme is well ahead of what could have been considered by Smeed and his panel - but somewhat behind what is now technically possible. But the principles that they described governing traffic flows and the economics of road traffic congestion are unchanged, and have now been applied in the centre of one of the world's leading cities. This is perhaps the greatest impact of the original scheme: it has shown that the principles of congestion charging are sound and that practical schemes are possible.

\section{DISCLAIMER}

The views expressed here are not necessarily those of Transport for London. 


\section{ACKNOWLEDGEMENTS}

The authors are grateful for the comments from referees on the original version of this paper.

Numerous colleagues and consultants contributed to the development of the congestion charging monitoring arrangements and to the analysis of data.

\section{REFERENCES}

Government Office for London (1995) The London Congestion Charging Research Programme. Her Majesty's Stationery Office, London.

Government Office for London (2000) Road Charging Options for London: A Technical Assessment. Her Majesty's Stationery Office, London.

Greater London Authority (2001) The Mayor's Transport Strategy. Greater London Authority, London.

Ministry of Transport (1964) Road Pricing: the Economic and Technical Possibilities. Report of a Panel led by Dr R J Smeed. Her Majesty's Stationery Office, London.

Owens D and Holroyd J (1973) The Glasgow Experiment: Assessments under Light and Very Low Flow Conditions. Transport and Road Research Laboratory, Report LR522.1973.

Wardrop JG (1952) Some theoretical aspects of road traffic research. Proceedings of the Institution of Civil Engineers, Engineering Divisions 1(3): 325-362.

\section{What do you think?}

To discuss this paper, please email up to 500 words to the editor at journals@ice.org.uk. Your contribution will be forwarded to the author(s) for a reply and, if considered appropriate by the editorial panel, will be published as discussion in a future issue of the journal.

Proceedings journals rely entirely on contributions sent in by civil engineering professionals, academics and students. Papers should be 2000-5000 words long (briefing papers should be 1000-2000 words long), with adequate illustrations and references. You can submit your paper online via www.icevirtuallibrary.com/content/journals, where you will also find detailed author guidelines. 